\title{
Las letras españolas, a comienzos de 1969, desde la perspectiva mexicana
}

\author{
FERNANDO VALLS \\ Universidad Autónoma de Barcelona (España) \\ https://orcid.org/0000-0001-5304-1138 \\ Presentación: 16 jul. 2021 | Aceptación: 9 sept. 2021 | Publicación: 15 dic. 2021
}

Cita recomendada: Valls, Fernando. 2021. «Las letras españolas, a comienzos de 1969, en perspectiva mexicana». Dictatorships \& Democracies. Journal of History and Culture 9: 157-182. doi: https:// dx.doi.org/10.7238/dd.voig.394370

Resumen: En 1969 la Revista de la Universidad de México, fundada en 1930, le dedicó un monográfico a las «Letras españolas». De esta publicación formaban parte los exiliados españoles Luis Rius y Vicente Rojo. El número se gestó el año anterior, una fecha histórica y literaria clave, cuyas repercusiones nos siguen afectando. El presente trabajo analiza su contenido y sus colaboraciones en relación con lo que pasaba entonces en México para acabar preguntándonos por qué se hizo este número, qué se quería mostrar y qué idea pretendía darse de nuestras literaturas, constatando que los mismos prejuicios o desconocimiento que se les achaca a los estudios del interior se reproducen en parte aquí, pues no se presta a los escritores del exilio republicano la atención que merecen. Palabras clave: letras y artes españolas, México, el exilio republicano, 1969

Spanish Literature in the early 1969 from a Mexican perspective

Abstract: In 1969 the Revista de la Universidad de México, founded in 1930, devoted a special issue to Spanish literature, «Letras Españolas». Luis Rius and Vicente Rojo, both Spanish exiles, worked for the journal. This particular issue was conceived the previous year, a key date in terms of historical and literary development whose consequences are still felt until this day. This paper is aimed at analysing its content and contributions taking into account the Mexican context. We will attempt to grasp why this issue was published, what it pretended to show and what vision of our literature wanted to portray, concluding that it partially replicates the same prejudices attributed to domestic studies, since Republican exile writers are not given the attention they deserve.

Keywords: Spanish art and literature, Mexico, the Republican exile, 1969

A comienzos de 1969 la Revista de la Universidad de México le dedicó un monográfico a las «Letras españolas» (vol. 23, núm. 5 y 6, enero-febrero). Dos exiliados republicanos españoles tenían en esta publicación un papel protagonista: el poeta Luis Rius (1930-1984), responsable de la sección de literatura, y Vicente Rojo (1932-2021), director artístico de la publicación. 
Había aparecido en 1930, casi a la par que la autonomía universitaria, y estaba dirigida entonces por el mexicano Gastón García Cantú. En sus noventa años de historia - hoy sigue publicándose - sus responsables han sido, entre otros, Francisco González Castro, su primer director, Jaime García Terrés, Luis Villoro (padre del escritor Juan Villoro), Leopoldo Zea, Diego Valadés, Hugo Gutiérrez Vega, Arturo Azuela, Ignacio Solares y, desde marzo de 2017, la escritora mexicana Guadalupe Nettel.

El 1968, año en el que debieron encargarse y escribirse los artículos para este número de la revista, es ya mítico en la historia por muy variadas razones: por la Guerra de Vietnam (la matanza de My Lai se produjo el 16 de marzo) tras más de una década de combates; por la llamada Primavera de Praga y la invasión de Checoslovaquia por parte de las tropas soviéticas el 20 de agosto; por los acontecimientos del Mayo francés que tantos cambios generaron en la vida cotidiana, en las costumbres; por los asesinatos de Martin Luther King y Robert F. Kennedy el 4 de abril y el 5 de junio, respectivamente; por la matanza en la plaza de las Tres Culturas en México el 2 de octubre, siendo presidente Gustavo Díaz Ordaz; por el golpe de Estado en Panamá de Omar Torrijos y el mayor Boris Martínez el 11 de octubre; por los Juegos Olímpicos en México entre el 12 y el 27 de octubre, y por la elección de Nixon como presidente de los Estados Unidos. ${ }^{1}$

1 Sobre la Guerra de Vietnam véanse las obras de Michael Herr (Despachos de guerra, 1980) y Max Hastings (La Guerra de Vietnam. Una tragedia épica, 2019); sobre la Primavera de Praga, las de Miguel Delibes (La Primavera de Praga, 1968), Peter Forbath (Siete estaciones, 2008) y Luis Zaragoza (Las flores y los tanques. Un regreso a la Primavera de Praga, 2018), y sobre el Mayo francés desde una perspectiva española, las de Miguel Amorós (1968. El año sublime de la acracia, 2014), Ramón González Ferriz (1968. El nacimiento de un mundo nuevo, 2017), Ana Muiña y Agustín Villalba (Esplendor en la noche. Vivencias de mayo. 1968, 2017) y Patricia Badenes Salazar (Fronteras de papel. El Mayo francés en la España del 68, 2018). Sobre el asesinato de Luther King, puede verse la novela de Antonio Muñoz Molina (Como la sombra que se va, 2014), y, sobre el de Robert Kennedy, los libros de Evan Thomas, Robert Kennedy: His Life, Nueva York: Simon \& Schuster, 20oo, y Chris Matthews, Bobby Kennedy. A Raging Spirit, Nueva York: Simon \& Schuster, 2017. Por otra parte, dejaron constancia de las matanzas de México en sus novelas Elena Poniatowska (La noche de Tlatelolco. Testimonios de historia oral, 1971), Luis Spota (La plaza, 1971), Fernando del Paso (Palinuro de México, 1977) y Vicente Leñero (Historias del $68,2018)$, que en su origen la concibió como un guion de cine. Sobre Torrijos, véase su libro La batalla de Panamá (1973) y el de Graham Greene (Descubriendo al general, 1985). Por último, sobre Nixon se pueden consultar las obras de Carl Bernstein y Bob Woodward (Todos los hombres del presidente, 1974; Los últimos días, 1976). Para un breve balance, véase Fernando Aramburu, «1968: cincuenta años después», Utilidad de las desgracias y otros textos, Barcelona: Tusquets, 2020, 58-61, que concluye afirmando que el 1968 supuso «un antes y un después en la historia reciente de la especie humana». 
En vista de estos acontecimientos, no deja de ser una terrible paradoja que el 1968 fuera declarado el Año Internacional de los Derechos Humanos por las Naciones Unidas.

En el terreno de las artes podrían destacarse novelas como la de Aleksandr Solzhenitsyn (El primer círculo), sobre la vida en los campos de trabajo del Gulag; la de Philip K. Dick (¿Sueñan los androides con ovejas eléctricas?), que adquirió un gran prestigio tras el estreno en 1982 de la película Blade Runner, de Ridley Scott; la de Ursula K. Le Guin (Un mago de Terramar), quizá su mejor novela en la tradición de lo fantástico, aunque en España no se tradujo hasta 1983; la de Halldór Laxness (Bajo el glaciar), y la de Carlos Castaneda (Las enseñanzas de Don Juan), libro a caballo entre el ensayo antropológico y la ficción que se publicó primero en inglés, siendo la tesis doctoral de su autor, y que apareció en castellano en 1974. En 1968 el Premio Nobel de Literatura lo obtuvo el japonés Yasunari Kawabata, autor de La bailarina de Izu (1926), País de nieve (1937), El sonido de la montaña (1954), El maestro de Go (1954), La casa de las bellas durmientes (1961) y Lo bello y lo triste (1964), obras publicadas en castellano en 1969, 1961, 1969, 2004, 1978 y 1977, respectivamente.

Por otro lado, en el ámbito del cine apareció 2001: una odisea del espacio, obra maestra de Stanley Kubrick; La extraña pareja, protagonizada por Jack Lemmon y Walter Matthau; La semilla del diablo, de Roman Polanski, con Mia Farrow y John Cassavetes, y El planeta de los simios, de Franklin J. Schaffner. También pudieron oírse los discos de Aretha Franklin, Otis Redding, Jimi Hendrix, The Beatles, John Lennon, The Rolling Stones, Bee Gees, Jethro Tull, Cream, Deep Purple, Pink Floyd, The Beach Boys, The Doors, Frank Zappa y The Velvet Underground. ${ }^{2}$

Por lo que respecta a la literatura española, aunque a veces se ha utilizado el marbete de "generación del 68" (como ha hecho Santos Sanz Villanueva, uno de los mejores conocedores de la materia, pero también el poco fiable Luis Racionero), me parece que no ha llegado a cuajar del todo. La novela, o la prosa narrativa, dio libros como Campo de los almendros,

2 Parte de estos datos provienen de Google y, por tanto, no siempre resultan del todo fiables. Siempre que ha sido posible, he intentado contrastarlos con otras fuentes de más credibilidad, como libros de historia, ensayos y enciclopedias. 
de Max Aub; La trama inextricable, de Juan Gil Albert; Lo que sucedió, de Eugenio F. Granell; El rapto de las sabinas (Premio de la Crítica), El reinado de Witiza e Historias de Plinio, de Francisco García Pavón; Prólogo a una muerte, de Antonio Prieto; Auto de fe (Premio Nacional de Narrativa), de Carlos Rojas; Las últimas banderas, de Ángel María de Lera; Volverás a Región, de Juan Benet; Inés just coming, de Alfonso Grosso; Fauna, de Héctor Vázquez Azpiri; Las tapias, de Antonio Martínez Menchén, y El mercurio, de José María Guelbenzu. En el terreno de la narrativa breve, del cuento, habría que citar La rebelión humana, de Ricardo Doménech. También fue importante en su momento la publicación de Tres días de julio, de Luis Romero, libro que oscila entre la historia y el reportaje.

La lírica nos dio la Antología de la nueva poesía española, de José Batlló, y volúmenes de autores de distintas edades y generaciones, como Breve son, de José Ángel Valente; Algo sucede, de José Agustín Goytisolo; Poeta de guardia, de Gloria Fuertes; Definiciones, de Angélica Becker; Las crónicas de mar y tierra, de Fernando Quiñones; Port-Royal, de Alfonso Canales; Coro de ánimas, de Diego Jesús Jiménez; La muerte en Beverly Hills, de Pere Gimferrer; Tigres en el jardín, de Antonio Carvajal; A través del tiempo, de Juan Luis Panero, o Cepo para nutria, de Félix de Azúa.

El teatro, por otra parte, no tuvo un año especialmente brillante, pues las obras más relevantes fueron Solo el amor y la luna traen fortuna, de Miguel Mihura; El cerco, de Max Aub; Las horas contadas, de José Ricardo Morales; La doble historia del doctor Valmy, de Antonio Buero Vallejo; Crónicas romanas, de Alfonso Sastre; Bestialidad erótica, de Fernando Arrabal; La amante, de Joaquín Calvo Sotelo; Los delfines, de Jaume Salom, y Primavera en la plaza de París, de Víctor Ruiz Iriarte.

En suma, cuando se acerca el final de la década de los sesenta, en la novela se consolida la denominada "generación del medio siglo", con obras notables de Juan Goytisolo, Juan Marsé o Juan Benet, aunque será en la primera mitad de los setenta cuando la novela española produzca sus libros más ambiciosos (obras de Gonzalo Torrente Ballester, Luis Goytisolo, Juan Marsé, Miguel Espinosa, Francisco Umbral o Eduardo Mendoza). En la poesía, hay que destacar las dos antologías de Castellet, la defensora del realismo, en sus dos ediciones de 1964 y 1965, respectivamente, y la dedicada a los Novísimos, que supondrá la aparición de un nuevo 
horizonte, el de la poesía culturalista. En el teatro, se consolidó la llamada "generación realista" - aunque a veces ese realismo no careciera de ribetes simbolistas-, compuesta por Antonio Buero Vallejo (El concierto de San Ovidio, 1962, y El tragaluz,1967), Alfonso Sastre (los cuentos de Las noches lúgubres, 1964; el ensayo Anatomía del realismo, 1965, y la pieza de teatro Flores rojas para Miguel Servet, 1967), y también por Lauro Olmo, Carlos Muñiz, José Martín Recuerda o José María Rodríguez Méndez, quienes se toparon a menudo con la censura, no pudiendo estrenar sus obras en el momento en el que les hubiera correspondido. El caso de Fernando Arrabal es distinto, pues adquirió su prestigio, me temo que exagerado, en los teatros de París y Nueva York, sin que acabara de cuajar definitivamente en España. Quizá lo mejor de su teatro pánico, y luego crítico, satírico, de raigambre vanguardista, pueda recogerse en una obra como El arquitecto y el emperador de Asiria (1966). Francisco Nieva se formó también fuera, como dramaturgo, escenógrafo y figurinista, en Francia e Italia, para luego triunfar en España, sobre todo en las postrimerías del franquismo y en los años de la Transición, con obras como La carroza de plomo candente (1973). Por último, no quiero dejar de citar el caso de Miguel Romero Esteo (Pasodoble, 1973), cuyas obras me parece que no se han representado como creo que merecerían. Y lo mismo podría decirse del teatro de los exiliados republicanos: ya hemos citado a Max Aub y José Ricardo Morales, apenas llevado a la escena. El paso del tiempo iría paliando este déficit, sobre todo en los casos de Rafael Alberti, Alejandro Casona y Max Aub. No así en el de José Ricardo Morales, quien merecería una atención mucho mayor de la que se le ha prestado, pues los montajes de sus obras han sido escasos. En suma, si el 1968 es una fecha histórica importante, por lo que respecta a la cultura española, será en vísperas, porque los grandes cambios, aunque ya vinieran gestándose, llegarían con la muerte de Franco, la desaparición de la censura y la implantación de la democracia.

El número de la revista que nos ocupa está dividido en dos partes, ya que al monográfico propiamente dicho se suma el suplemento Hojas de Crítica, con su propia paginación independiente, también dedicado a la literatura española. Así, en la portada del número aparece una obra de Antoni Tàpies, sobre cuya trayectoria se reproduce también un fragmento del libro que le dedicó el crítico Francesc Vicens, militante del PSUC, a la que sigue, en las 
páginas interiores, una «Galería de obras», con trabajos de Antonio Saura, serigrafías, pinturas de Ràfols Casamada, Argimon y Tàpies, además de esculturas de Chillida. Por otra parte, este suplemento está ilustrado con grabados de artistas españoles del grupo Estampa Popular: María Girona, F. Álvarez, Albert Ràfols Casamada, Todó, Manolo Valdés, Joan Hernández Pijuan, Esther Boix, F. Vilas, Ortiz Valente, Narotzky, Guinovart, Gorris, Clavo (una cabeza de Unamuno) y Mauri (escribo los nombres catalanes tal y como aparecen citados). A esta estética, el crítico José María Moreno Galván (1923-1981) ${ }^{3}$ le dedica un breve comentario, donde viene a decir que el realismo de ese momento ya no responde a una fatalidad propia del español, sino a una voluntad, a una decisión personal de cultivarlo, pues el realismo «es el testimonio de una realidad cuyo objetivo estriba en comunicarnos para entendernos [...], haciendo nuestra la voz de los demás y ofreciéndoles a los demás nuestra propia voz». Por ello —continúa Moreno Galván — la asociación de dos palabras, "realismo” y "social”, adquiere plena coherencia. Aunque se refiera a la pintura, en el caso de la literatura este debate diría que quedó zanjado tras la publicación de Tiempo de silencio (1962) y el coloquio de Madrid de 1963 «Realismo y realidad en la literatura contemporánea», en especial tras las lúcidas intervenciones de Mary McCarthy, ${ }^{4}$ a pesar de que en la última década algunos críticos hayan reivindicado esta tendencia novelística de finales de los cincuenta y primeros sesenta, pero con escaso crédito y fortuna.

Además de resaltar los textos de creación de Vicente Aleixandre, Juan Gil Albert (un fragmento de Tobeyo o del amor. Homenaje a México), León Felipe (dedicado «a Juan Rejano, viejo amigo / y hombre bueno porque

3 Moreno Galván destacó como periodista cultural y crítico de arte, y fue el primer promotor de la carta dirigida a Fraga sobre la represión de los mineros en Asturias en 1963. De formación autodidacta, estuvo vinculado a la izquierda comunista como un intelectual comprometido, por lo que fue encarcelado. Colaboró en revistas como Cuadernos Hispanoamericanos, Goya, Papeles de Son Armadans, Gaceta Ilustrada, Destino, Cuadernos de Ruedo Ibérico y Triunfo. Entre sus libros destacan Introducción a la pintura española (1960), Autocrítica del arte (1965, reeditado en 2012), Pintura española. La última vanguardia (1969) y Epistola moral y otros artículos sobre arte (2012), además de diversas monografías sobre pintores y museos. Era hermano del artista Francisco Moreno Galván y padre de la editora Carola Moreno, de Barataria. En una conversación reciente de Juan Cruz ( $E l$ País, 5 jul. 2021, 26) con el historiador del arte Valeriano Bozal, este afirmaba que en los años sesenta Moreno Galván había sido el crítico de arte más importante de España.

4 Cf. Josep Maria Castellet, Los escenarios de la memoria, Barcelona: Anagrama, 1988, 204-224. 
Sí»), ${ }^{5}$ Ramón J. Sender, Juan Goytisolo (un fragmento de Reivindicación del conde don Julián, novela entonces en preparación), Juan Rejano («Pequeñas elegías») y Antonio Ferres («Balanza del tiempo»), unos en verso y otros en prosa, me gustaría llamar la atención especialmente sobre las colaboraciones de Salvador Espriu (tres poemas traducidos al castellano por José Batlló) y Agustí Bartra (el poema «Cartel para los muros de mi patria») como representantes de la poesía catalana. En cambio, la literatura gallega y vasca están ausentes, sin que se nos proporcione explicación alguna al respecto. El resto de las colaboraciones del número se ocupan de la novela (Rafael Conte, Daniel Sueiro ${ }^{6}$ y Alberto Míguez) y de la poesía (Ricardo Gullón), sin que falten nunca las referencias - aunque sean escasas- a lo que se escribe en el exilio.

Debe destacarse también el artículo de Tuñón de Lara, «¿Dos Españas?», cuestión que hoy vuelve a ser de actualidad tras la defensa de una tercera España por ensayistas como Paul Preston o Andrés Trapiello. ${ }^{7}$ Tuñón repasa la historia de esta idea y nos recuerda que los conservadores españoles defendieron «la consustancialidad de la patria con la religión», punto de partida para negar a los republicanos - en su mayoría, defensores de un cultura laica - su condición de españoles. El historiador cree, como Antonio Machado, que la verdadera España, plural aunque sin romper la unidad, está situada en el porvenir, es una realidad futura (p. 12). En otro artículo, «La novela española, hoy. Una literatura del subdesarrollo», el crítico Rafael Conte sostiene que la palabra que mejor definía la novela

5 En un recuadro se anuncia el monográfico de Ínsula (núm. 265, diciembre 1968) dedicado al poeta exiliado con motivo de su muerte en 1968, en el que colaboran, entre otros, Gerardo Diego, Guillermo de Torre, Max Aub, Manuel Durán, Luis Rius (autor de una biografía del poeta publicada el mismo 1968), Leopoldo de Luis y José Luis Cano. Se incluyen, además, poemas de Aleixandre, Jorge Guillén, Ángela Figuera Aymerich, Tomás Segovia y Ramón de Garciasol.

6 En un destacado, en la página 21, se da la noticia de que Daniel Sueiro ha obtenido el Cuarto Premio Alfaguara con su novela Corte de corteza (1969).

7 Véase Paul Preston, Las tres Españas del 36, Barcelona: Plaza \& Janés, 1998; Javier Ruiz Portella, ed., La Guerra Civil: ¿dos o tres Españas?, Barcelona: Áltera, 1999. Para Trapiello (Las armas y las letras. Literatura y Guerra Civil (1936-1939), Barcelona: Destino, 2019, 19, 21, 80, 123, 195, 246, 247, 473, 517 y 619), esa tercera España tolerante la representaban gente como Salvador de Madariaga, Gaziel, Chaves Nogales o el editor Josep Vergés. Preston, en el prólogo a su libro, y en las páginas 211-213 y 287, añade los nombres de Ortega y Gasset, Niceto Alcalá Zamora, Julián Besteiro y el cardenal Vidal y Barraquer, entre otros. Ruiz Portella incluye también a Azaña e Indalecio Prieto. Puede verse también lo que digo al respecto en una reseña que aparece en este mismo número de la presente revista. 
española a finales de los años sesenta era "posibilidades", pues durante la postguerra «la literatura quedó reducida al consumo de la burguesía» (p. 21), y los escritores se encontraron, sintetiza Conte, «sin maestros, que estaban en el exilio; sin libros para leer; aislados de la cultura y el arte de su tiempo» (p. 20). Así, mientras que en América podían conocer, traducidas al castellano, las obras de Sartre, Camus, Faulkner, Moravia, Pratolini, Heidegger, Barth o Bertrand Rusell, en España tenían que contentarse con las novelas del húngaro Lajos Zilahy (1891-1974), el inglés Cecil Roberts (1892-1976), la austriaca Vicki Baum (1888-1960) o, en el mejor de los casos, Somerset Maugham (1874-1965) (p. 20). En este recorrido histórico por la narrativa española de postguerra y por los intereses de los lectores españoles destacaría dos aspectos que pone de manifiesto el crítico: el impacto que causó la nueva literatura hispanoamericana que surgió en los sesenta y la renovación estética que se aprecia en tres novelas españolas de 1968 - El mercurio, de José María Guelbenzu, Volverás a Región, de Juan Benet, publicada en 1967, y Fauna, de Vázquez Azpiri-, pero cabe resaltar también que en ningún momento se refiere a las novelas de Cela, Delibes, Torrente Ballester, Martín Santos, Ignacio Aldecoa, Ana María Matute o Rafael Sánchez Ferlosio. En cambio, insiste en que el lector español debería conocer la obra de los narradores del exilio, y cita a Max Aub, Sender, Andújar o Ayala, pero se olvida de Rosa Chacel, de Arturo Barea o de Serrano Poncela. También desea que se conecte con los novelistas en lengua catalana (alude a Llorenç Villalonga, Salvador Espriu, Rodoreda, Pedrolo y Porcel, aunque no tiene en cuenta a Joan Perucho, Pere Calders o Joan Sales, todos ellos autores de mucho más calado que el prolífico autor del Mecanoscrit del segon origen), que considera pertenecientes a la literatura española, confundiendo cultura con literatura. Afirma, además, que «los novelistas [españoles] no han penetrado todavía en el pueblo» (p. 22). Se trata de un artículo de alguien que conoce la materia pero que presenta sus ideas un tanto desordenadas, mostrándose demasiado apresurado en su articulación y en sus juicios, aunque hoy, con la perspectiva que nos proporciona el paso del tiempo, resulta más fácil apreciar el panorama de Rafael Conte.

El trabajo de Sueiro —entonces un joven novelista que se definía como «comprometido [...] con el mundo inmediato», y que entendía la literatura DICTATORSHIPS \& DEMOCRACIES 9 (2021) - E-ISSN: 2564-8829 - PUNCTUM, UNIVERSITAT OBERTA DE CATALUNYA \& FUNDACIÓ CARLES PII SUNYER 
«como revelación hacia los demás, como forma de expresión, como modo de vida y como ejercicio vivo del pensamiento y del lenguaje» (p. 30 y 35), pero cuya obra no acabó nunca de cuajar, aunque sí lo tenemos hoy por un buen escritor de cuentos y un oportuno reportero de largo alcance (eso que se llamó "nuevo periodismo") - es más bien «una especie de confesión», en la que se muestra pesimista, cansado, debido a los escasos avances literarios de los componentes de su generación, la de los cincuenta, sobre la que concluye: «La "nueva oleada" se ha convertido en la oleada inmóvil del silencio». Y, sin embargo, no parecen ciertos del todo sus temores, porque muchos de ellos, a la altura de 1968, ya habían dado obras de consideración, tanto en la novela como en el cuento, y pronto publicarían nuevos textos significativos. Esa crisis de la novela española, que no ocurre en la escrita fuera de España por los exiliados, Sueiro la vincula con «la crisis casi total que atraviesa la novela en el mundo», con la excepción de la narrativa hispanoamericana (p. 31). Por otra parte señala algunos aspectos más sabidos y otros que también debemos tener en cuenta: la falta de ambiciones universales de nuestros narradores (Alberto Míguez, en un trabajo que luego comentaremos, constata en el mismo sentido que «nuestro país [se encuentra] encerrado en el ghetto», p. 4); el error de dirigirse a unos lectores que no los leen; la soledad en la que trabajan, sin apenas relación con sus colegas - pero que sabemos que no ocurría entre determinados grupos de escritores tanto de Madrid como de Barcelona-; la censura; la relación con los editores; la escasa presencia en los medios de difusión, sobre todo en la prensa, y cómo los novelistas, puesto que los medios no cumplen con su función de presentar y analizar la realidad, debido a la falta de libertad, tienen que ocuparse de temas que los lectores deberían conocer a través de la prensa, la radio y la televisión. En el repaso que hace Sueiro, tanto de la narrativa del interior, donde mezcla lo bueno con lo regular, como de la del exilio se olvida de nombres importantes, como Gonzalo Torrente Ballester y Miguel Delibes, pero también de Francisco Ayala, de Rosa Chacel y de Segundo Serrano Poncela. Cuando se acerca a los autores de su generación, cita a Ignacio Aldecoa, a Juan Goytisolo y a Juan García Hortelano, pero no recuerda a Ana María Matute, ni a Juan Marsé. Le preocupa el que algunos de esos nombres prometedores lleven tiempo sin publicar novelas, como ocurre 
en los casos de Sánchez Ferlosio, Carmen Martín Gaite y Luis Goytisolo. Como sabemos ahora, el primero no volvería a cultivar el género, pero los dos restantes, en la siguiente década, publicarían grandes obras, entre otras Recuento (1973) y El cuarto de atrás (1978). El trabajo de Sueiro concluye haciéndonos la promesa siguiente, mientras escribe la que sería su próxima novela: «Voy a proponerme [...] ser sencillamente un hombre libre y vivo, un escritor libre y vivo» (p. 36). Recuérdese que estaba a punto de aparecer Corte de corteza (1969) y que su siguiente narración extensa sería El cuidado de las manos (1974).

El artículo de Ricardo Gullón (1908-1991) sobre la poesía está dedicado a Juan Marichal, un profesor estrechamente vinculado con el exilio, en lo personal y en lo profesional, a quien le debe la expresión "voces del silencio" (esas voces, nos dice, «eran voces fieramente humanas»), que tomó prestada de Malraux y que le sirve para titular el artículo. Gullón traza un breve panorama de la poesía de la postguerra destacando tendencias (una poesía escapista y otra temporalizadora) y recordándonos que la lírica se anticipó a la novela y al ensayo «en la expresión de una situación colectiva», pues «en determinados momentos el canto personal debe ceder el paso al canto general», aunque al profesionalizarse la protesta «se institucionalizó en una retórica, empezó a perder eficacia». Para Ricardo Gullón los predecesores de esa estética fueron Antonio Machado, Pablo Neruda, César Vallejo, Rafael Alberti y Miguel Hernández. Llama también la atención sobre la tendencia tremendista («fidelidad a lo real en intuición y expresión», p. 46), representada por los poetas de la revista Espadaña; resalta los distintos círculos de amistad que surgieron en Madrid, esos que Sueiro — en cambio - echaba de menos, además de los libros «más significativos del cambio que estaba registrándose» en los primeros años de la postguerra: Sombra del paraíso, de Aleixandre, e Hijos de la ira, de Dámaso Alonso, ambos de 1944, y la colección «Adonáis». Tras ellos, se centra en una generación desarraigada, según Blas de Otero, en la que incluye libros de José Hierro, Gabriel Celaya, José Luis Hidalgo, Ildefonso M. Gil y Victoriano Crémer, aunque los tonos empleados por ellos —nos advierte con razón - no fueran los mismos. 
En 1952 se publica la Antología consultada de la joven poesía española, de Francisco Ribes, ${ }^{8}$ fórmula de la que luego se ha abusado, compuesta por nueve poetas (Carlos Bousoño, Gabriel Celaya, Victoriano Crémer, Vicente Gaos, José Hierro, Rafael Morales, Eugenio G. de Nora, Blas de Otero y José María Valverde), que, además de sus versos, nos proporcionaban unas breves declaraciones programáticas en las que la mayoría defendía que «la poesía había de ser realista y social». Pero lo social, apunta Gullón, «empezó a sonar a consigna», incurriendo «en pecado de academicismo». La década de los sesenta fue machadiana (no alude, sin embargo, a los homenajes de 1959), y en esa tónica «ha vuelto a parecer legítima la interiorización más honda, la penetración y circulación de las secretas galerías del alma [...], y esa recuperación de la intimidad es signo acusado de la poesía actual» (p. 4448). Concluye Ricardo Gullón afirmando que «la lírica de los veinticinco años de censura [...] no para todos fueron de paz» (Míguez, en su artículo, también se refiere a «estos treinta años de paz» con ironía), en alusión a la celebración triunfalista y hueca del régimen en 1964.

¿Qué no tiene en cuenta Gullón, desde nuestra privilegiada perspectiva actual? Todos los intentos simbolistas y vanguardistas, a cargo de Juan Eduardo Cirlot, Carlos Edmundo de Ory, Ángel Crespo, Gabino Alejandro Carriedo, Miguel Labordeta o Antonio Gamoneda, con sus correspondientes revistas (por ejemplo, las postistas), aunque tuvieran escasa difusión, la generación del medio siglo (las colecciones de libros vinculadas a ellos, «Colliure»y «Poesía para todos») y la antología de Castellet, en sus dos versiones de Veinte años de poesía española y Veinticinco años de poesía española, de 1959 y 1964, respectivamente. Pero lo más asombroso es que, sin problemas de censura y residiendo en América desde 1953, primero en Puerto Rico y luego en los Estados Unidos, no prestara atención en este artículo a los poetas del exilio, con quienes debía de estar en contacto. ${ }^{9}$

8 Se editó en las Artes Gráficas de los Hermanos Bedia, de Santander. En 1983 la reeditó en edición facsímil Prometeo Editorial, de Valencia, con prólogo de Josefina Escolano.

9 Debe recordarse, sin embargo, que Ricardo Gullón se ocupó de la poesía del exilio, sobre todo de la obra de Antonio Machado, Juan Ramón Jiménez y Jorge Guillén, en libros como La poesía de Jorge Guillén (1949), escrito en colaboración con José Manuel Blecua; Conversaciones poéticas con Juan Ramón Jiménez (1958); Las secretas galerías de Antonio Machado (1958); Estudios sobre Juan Ramón Jiménez (1960); Relaciones amistosas y literarias entre Antonio Machado y Juan Ramón Jiménez (1961); Relaciones amistosas entre Juan Ramón Jiménez y los Martínez Sierra (1961); El último Juan Ramón 
Las Hojas de Crítica, que ocupa la segunda parte del número, se inicia con un sugestivo artículo de Alberto Míguez ${ }^{10}$ sobre las clases sociales y la narrativa de la postguerra, en el que tras plantearse si la novela «sirve para darnos una imagen más exacta, real y dinámica de nuestra sociedad española», viene a concluir que «ha sido lo que fue la sociedad en la que nació», pues responde al humus en el que se produjo, ya que esas obras son «el producto acabado (no perfecto) de la burguesía ilustrada, autosatisfecha, triunfalista y hermética de la España de la segunda mitad de este siglo», pues «solo una clase social - la burguesía - ha podido expresar sus frustraciones, triunfos y deseos manifiestos, o contradicciones a través del vehículo literario». Así, continúa Míguez, la narrativa que surge en España tras la Guerra Civil «ha sido una novela burguesa, escrita por burgueses y para burgueses», y, cuando los escritores han querido ocuparse de otros mundos - pienso yo en el caso de Juan Goytisolo, que él mismo ha reconocido-, «fracasan estrepitosamente» (p. 2-4), nos dice. Quizá habría que matizar que algunos de esos autores sería más preciso tacharlos de pequeñoburgueses (en el sentido que lo ha hecho la tradición marxista,

Jiménez. Así fueron los ríos (1968); Una poética para Antonio Machado (1970); Antonio Machado (1973), recopilación de trabajos críticos en colaboración con A. W. Phillips, y Los espacios poéticos de Antonio Machado (1987).

10 La presencia de Alberto Míguez (La Coruña, 1940 - Madrid, 2009) en este monográfico quizá sea la más sorprendente, junto a la de Jorge Arturo Ojeda, al menos para un lector español, pues como él mismo reconoce: «No soy [...] crítico literario» (p. 2). Míguez estudió en la Universidad de Santiago de Compostela y en la Escuela Oficial de Periodismo, en Madrid, y, tras dirigir la sección de cultura del diario Madrid, destacó sobre todo como experto en política internacional —cubrió el golpe de Estado de Pinochet, la revolución portuguesa de los claveles y la política marroquí, siendo (además) enviado especial a América Latina- y como corresponsal diplomático, trabajando en ese cometido en La Vanguardia, El País (fue redactor jefe de la sección internacional en 1977), ABC y ya en el siglo xxI en los diarios electrónicos Libertad Digital (2000-2006), Estrella Digital (2009), así como en la agencia Firmas Press. Es cierto, sin embargo, que cultivó la crítica literaria en La Voz de Galicia, en el diario Madrid en su época más aperturista, cuando lo dirigió Antonio Fontán y formaban parte de la redacción Miguel Ángel Aguilar y José Oneto, y en La Vanguardia. Además, prologó una edición de El audaz (Editorial Andorra, 1972), de Galdós. Era francófono y afrancesado, quizá por influencia de Lilian Dublane, su esposa, traductora francesa. Entre sus libros se cuentan El pensamiento político de Castelao. Antología (París: Ruedo Ibérico, 1965, con ilustraciones de Luís Seoane y reeditado en Nova Galiza en 1975 en edición bilingüe); Galicia: éxodo y desarrollo (Madrid: Cuadernos para el Diálogo, 1967); Galicia: de la estética al subdesarrollo (Algorta: Zero, 1970); El pensamiento filosófico de Julián Besteiro (Madrid: Cuadernos Taurus, 1971); Marruecos en la encrucijada (Madrid: Castellote, 1973), y, en colaboración con Antonio Sánchez Gijón, El Atlántico sur. Un estudio político estratégico (Madrid: Instituto de Cuestiones Internacionales, 1984). 
o en el terreno de la estética literaria de Brecht), y sus obras como el producto de esa mirada sobre el mundo. Para Míguez hubo seis novelas importantes en esos treinta años de postguerra: Nada (1945), El Jarama (1956), Nuevas amistades (1959), Tiempo de silencio (1962), Últimas tardes con Teresa (1966) y Cinco horas con Mario (1966). Excepto dos de ellas, la última y la antepenúltima, las demás fueron galardonadas con el Premio Nadal o el Biblioteca Breve. Pero cualquier lector informado podría echar de menos en esa breve lista La colmena (1951), Industrias y andanzas de Alfanhuí(1951) o Los hijos muertos (1958). Alberto Míguez recuerda, además, la importante presencia de la Guerra Civil en las novelas tanto del interior como del exilio, y, como había hecho Rafael Conte, se detiene en dos de 1968: Réquiem por todos nosotros, de José María Sanjuán, Premio Nadal, y Fauna, de Vázquez Azpiri, en la que coincide con aquel.

El artículo de Federico Álvarez ${ }^{11}$ sobre La familia de Pascual Duarte (1942) debe de ser el mismo texto que figuró como prólogo a la edición de la novela aparecida en La Habana en 1968. Lleva a cabo una lectura muy crítica del libro, pues considera que, más que iniciar una nueva etapa de la narrativa española, como venían repitiendo los estudiosos de la materia, cierra aquella otra que iniciaron los autores del 98. En cambio, para él, Nada, la novela de Carmen Laforet, que tanto apreciaron los exiliados (Guillermo de Torre, Max Aub, Arturo Barea, Esteban Salazar Chapela o Jorge Semprún), era otra cosa. Antes de entrar en el análisis estricto de la obra de Cela, Federico Álvarez repasa lo que dieron de sí los diez años anteriores a la Guerra Civil, que sintetiza en «esteticismo, deshumanización, narcisismo y petulancia», lo que Max Aub llamó «la cagarrita literaria», aunque él mismo la cultivara: un «extraño humorismo de triste fama: Jardiel Poncela, Fernández Flórez, Edgar Neville», juicio más ideológico que literario que comparte - y que quizá heredó- con su suegro Max Aub, y la pervivencia de la novelística de Azorín, Baroja, Valle-Inclán y Pérez de Ayala. Sin embargo, no parece tener en cuenta las dos grandes novelas de esos años de vísperas: Tirano Banderas (1926) e Imán (1930). Por otra parte,

11 Federico Álvarez, en la fecha en la que se publicó este artículo, acababa de licenciarse en Letras en México; lo hizo en 1965, con 38 años, y vivía en Cuba, donde era profesor de Literatura Española en la Universidad de La Habana, identificado con las ideas de la revolución. Había traducido Significación actual del realismo crítico (1963), de Lukács. 
el exilio era para él un «terreno nada fértil para una novelística que tenía su nueva razón de ser en el país que se abandonaba dramáticamente», pero, sin embargo, dio buenas obras, y algunas de ellas excelentes, que están en la memoria de todos los lectores atentos. Me refiero - selecciono las que me parecen mejores - a obras de Max Aub (Vida y obra de Luis Álvarez Petreña, 1971; El laberinto mágico, 1967; Jusep Torres Campalans, 1958, y Juego de cartas, 1964), R. J. Sender (Crónica del alba, 1966, y Mosén Millán, 1953; luego Réquiem por un campesino español, 1960), Álvaro Fernández Suárez (Hermano perro, 1942), Paulino Masip (El diario de Hamlet García, 1944), Esteban Salazar Chapela (Perico en Londres, 1947, y Desnudo en Piccadilly, 1959), Arturo Barea (La forja de un rebelde, 1951, si me ciño a la versión en castellano), Francisco Ayala (Muertos de perro, 1958, y El fondo del vaso, 1962), Eugenio F. Granell (La novela del indio Tupinamba, 1959), Rosa Chacel (La sinrazón, 1961) y Segundo Serrano Poncela (Habitación para un hombre solo, 1963). Lo que Federico Álvarez achaca a la novela de Cela es «el facilismo de lo violento, de lo truculento, de lo brutal»; en suma, «su irracionalismo, tremendismo y "españolidad"», aunque aparezca vertido - reconoce - en una prosa de indudable calidad.

Jorge Arturo Ojeda ${ }^{12}$ parece sentirse incómodo con la lectura de $E l$ Jarama, de Sánchez Ferlosio, sobre la que viene a concluir que se trata de «la gran metáfora de la vida común que fluye por lo que en un tiempo fue campo de batalla», pues quizá esperaba otra historia distinta en un espacio histórico, lo que hoy llamamos un "lugar de la memoria" con chirriante galicismo. Así, comenta decepcionado: «Quizá no puede haber memoria más patética, pues se pierde en la nadería lo que costó tanta sangre». El caso es que los personajes, nos dice, apenas se diferencian, son jóvenes, pero «ninguno es representativo de la juventud», y viven en un presente banal, pues «nadie tiene historia ni pretende futuro». Se aburren, entablan «discusiones preñadas de gazmoñería», pues, en realidad, la novela plantea

12 A comienzos de 1969 Jorge Arturo Ojeda (Ciudad de México, 1943) era un joven narrador que había publicado cuentos, una novela (Como la ciega mariposa, 1967), poemas y ensayos. Con posterioridad a esa fecha siguió cultivando esos mismos géneros, pero también la literatura de viajes y la traducción (Novalis, Himnos a la noche, 1999). Entre sus numerosos estudios me llaman la atención dos libros sobre Juan José Arreola (La lucha con el ángel, 1969) y Octavio Paz (La cabeza rota. La poética de Octavio Paz, 1983), así como un artículo sobre G. A. Bécquer. 
un problema mayor: la incomunicación. Creo que la narración de Sánchez Ferlosio se ocupa además de otras cuestiones que deben entenderse en el contexto de la historia española de la postguerra, de su tradición literaria más reciente — que Ojeda encuentra en Galdós, «entre otros [escritores] posteriores al Siglo de Oro», lo que no es mucho precisar-, de un objetivismo que vino de fuera y de la lengua de la prosa narrativa en castellano. Sea como fuere, Sánchez Ferlosio no se quedó satisfecho de su novela, y siempre que ha podido la ha criticado, aunque por otras razones muy distintas de las expuestas en este artículo..$^{13}$

El crítico argentino Juan Carlos Curutchet (1942-2001) ${ }^{14}$ se ocupa de Señas de identidad (publicada originariamente en 1966; aunque esta edición de Joaquín Mortiz circulaba en España, no pudo publicarse en el país hasta 1976), novela que considera, junto a Tiempo de silencio (1962), entre las mejores españolas del momento, un juicio que perduró a lo largo de décadas. Recuérdese que en 1968 Juan Goytisolo había publicado un conjunto de ensayos titulado El furgón de cola. El autor se plantea el problema de las dos Españas como un tópico que ha causado estragos (como ya hemos visto, en este mismo número lo había tratado Tunón de Lara); en ese sentido, trata la idea del paisaje de Castilla como esencia de España y la confrontación entre las ideas emanadas del poder y las de los intelectuales críticos para defender una tercera España: «La España históricamente

13 En el libro de entrevistas coordinado por José Lázaro (Diálogos con Ferlosio, Madrid: Triacastela, 2019, 66, 73, 80, 105, 107, 117, 387, 421 y 459) aparecen varios comentarios despreciativos del autor sobre su novela. Así, afirma que prefiere Alfanhuí a El Jarama, novela que dice detestar, aunque esté mejor escrita, pues su prosa es sintácticamente pobre. Su escritura, insiste, fue un error y el objetivismo que se le ha atribuido era «casi una falsificación»: «Una novela tiene que salir de paisajes, de emociones, no de esta manera». Así, se lamenta, se le ha dado demasiada importancia al ahogamiento de la muchacha, siendo como fue una metedura de pata tremenda. «Fue», sigue, «un "producto" profesional y no una obra [...], es un artificio que no se sabe a qué viene». Pero, aunque la aborrezca, reconoce también que es una vaca que le ha dado mucha leche. Concluye afirmando que El Jarama es una invención de Castellet. Y, sin embargo, otros prestigiosos críticos, historiadores de la literatura y escritores la han tenido en gran estima, como Darío Villanueva, E. C. Riley, Santos Sanz Villanueva, Geneviève Champeau, Gonzalo Hidalgo Bayal o Sergio Beser.

14 Entre finales de los años sesenta y inicios de los setenta residió en España colaborando en revistas como El Urogallo, Cuadernos Hispanoamericanos e Índice, como crítico literario y ensayista. Dedicó un libro a Cortázar — Julio Cortázar o la crítica de la razón pragmática (Editora Nacional, 1972)—, y dos más a la literatura española: Introducción a la novela española de postguerra (Alfa, 1966), y A partir de Luis Martín Santos. Cuatro ensayos sobre la nueva novela española (Alfa, 1973). 
posible», afirma Curutchet, «sustraída al dualismo del mito de la España Eterna y su reversión en el mito de la leyenda negra; esta es la España de Clarín y de Cervantes, de Larra y de Quevedo», y me imagino —añado yoque será también la de los novatores, los ilustrados, los románticos liberales, con Blanco White, Larra y Espronceda a la cabeza, los institucionistas, Galdós, Leopoldo Alas, Emilia Pardo Bazán, Unamuno, Antonio Machado, Juan Ramón Jiménez, Valle-Inclán, Ortega y Gasset, Manuel Azaña, Manuel Chaves Nogales, Luis Cernuda, Max Aub y Francisco Ayala. Por otra parte, el crítico argentino repasa la historia de la narrativa española contemporánea, elogiando sobre todo a Valle-Inclán, a quien considera «el narrador más radicalmente moderno de la literatura española de este siglo». Afirma, además, que la novela no puede seguir ocupando un espacio que ahora utiliza mejor el cine, la prensa y la televisión, aunque observa que estos medios no han conseguido mostrar, en cambio, la descripción de los procesos de conciencia, tal y como ocurre en las narraciones de Joyce, Faulkner, D. H. Lawrence y otros, y en ese momento en España en las obras de Luis Martín Santos y Juan Goytisolo, cuyas novelas son «afortunada[s] respuestas a las exigencias de esa nueva realidad», que es algo que no habían logrado Baroja o Cela, apegados a planteamientos tradicionales. Representan «yoes en erupción, de estos complejos mundos interiores cada vez más laberínticos y abigarrados, y la conciencia de la insuficiencia de las técnicas tradicionales para expresar esta nueva realidad», aunque Curutchet recuerda que quizá aparecieran por primera vez en la obra de Stendhal. La novela de Goytisolo está protagonizada por Álvaro Mendiola, alter ego del autor, un fotógrafo exiliado voluntariamente a Francia que regresa en el verano de 1963 en busca de su identidad, una indagación que resulta angustiosa. Pero de todo lo que comenta Curutchet lo que quizá nos interesa más ahora sea la utilización de la sátira, la desmitificación de valores, actitudes y conductas, el cuestionamiento de una cierta mitología creada por los exiliados republicanos, sobre todo en París, en las escenas que transcurren en el café de Mme. Berger. En suma, nos dice: «Toda esta novela es una tentativa de dotar de una coherencia histórica, una proyección social y una significación humana [a] esa imagen abigarrada y contradictoria de una España circunscrita por los teóricos tradicionales a afiche de turismo». Y con ella, y con la obra de Martín Santos, dice 
Curutchet en la conclusión, la novela española ha encontrado un camino legítimo, «después de numerosos y contradictorios intentos más o menos fracasados». Como ha podido observarse en las citas, Curutchet es muy dado a las especulaciones abstractas y a hacer juicios taxativos, y esa retórica suele envejecer mal. Hoy seguimos manteniendo la misma opinión sobre la novela de Martín Santos, pero me parece que la de Juan Goytisolo ha envejecido peor sin haber conseguido destruir la España sagrada, aunque el país haya cambiado muchísimo, y para bien, desde la fecha en la que se publicó. El caso es que la prosa de Goytisolo resulta pobre, las escenas y juicios demasiado maniqueos, el experimentalismo a veces impostado, y tampoco ayuda la supresión del capítulo sobre la estancia en Cuba que afecta a la descompensación de la estructura. ${ }^{15}$

Eduardo Naval (19??-2004) ${ }^{16}$ se ocupa de analizar Réquiem por todos nosotros (1967), novela ganadora del Premio Nadal ${ }^{17}$ escrita por José María Sanjuán (1937-1968), quien falleció unos meses después, siendo muy joven y habiendo comenzado una prometedora carrera como narrador y periodista. Naval empieza trazando un breve recorrido por la historia del premio para centrarse en la segunda parte del artículo en el análisis y valoración de la novela, que al fin y a la postre no resulta positivo: «Pretendió, sin lograrlo totalmente, hacer una crítica en la que se presentan paralelamente el atraso de España en varios aspectos, y la vida intrascendente de unas cuantas personas [...]. Pero el esfuerzo se quedó a medio terreno por la rabia con que trabaja el narrador». Y, más adelante, Naval comenta que esa rabia «podía haber sido aprovechada en otra disciplina, ya que llevada a la novela no supo tratarla con la suficiente malicia y soltura». Acaba el artículo lamentando la muerte de Sanjuán, un autor que le parecía «bien pertrechado para, en pocos años, con mejores armas, haber logrado su

15 Para una visión de conjunto de la obra de Juan Goytisolo, y seguramente más generosa, véase la síntesis de Santos Sanz Villanueva, «Juan Goytisolo», en Domingo Ródenas de Moya, ed., 10o escritores del siglo XX. Ámbito hispánico, Barcelona: RBA, 2012, 290-298.

16 Se trata de un prestigioso traductor del portugués que había versionado obras de Lídia Jorge, Jose Saramago, Eça de Queiroz y Mia Couto, entre otros, así como los fados de Mísia. Pero también cultivó el artículo, colaboró en la revista El Urogallo, estuvo entre los fundadores de la Editorial Alfaguara y, además, fundó la librería madrileña El Galeón. No he logrado saber su fecha de nacimiento.

$17 \mathrm{Al}$ año siguiente, el 6 de enero de 1968, Álvaro Cunqueiro obtuvo el Nadal con su novela Un hombre que se parecía a Orestes (1968). 
empeño en una novela redonda». Una vez fallecido Sanjuán, Umbral le dedica, el 9 de enero de 1969, un comentario despreciativo en una carta que dirige a Miguel Delibes, tras no haber logrado ganar el Premio Nadal, al que se presentaría en diversas ocasiones, hasta obtenerlo finalmente con Las ninfas en $1975 .^{18}$

En cambio, Valquiria Wey ${ }^{19}$ se ocupa de Míster Witt en el cantón (1935), novela histórica de R. J. Sender que obtuvo el Premio Nacional de Literatura en su año de publicación, cuyo argumento repasa y sintetiza para concluir: «De este cuadro histórico, fin de siglo, de esta novela de líneas tan clásicas queda la constancia de la actitud heroica de un pueblo, el asentamiento de una derrota que se volvería a repetir y una pasión y penetración psicológicas absolutamente modernas». Sorprende, sin embargo, que no eligiera para su análisis una obra de más entidad literaria, como Imán, Crónica del alba o incluso Mosén Millán.

Dalibor Soldatić (1947), ${ }^{20}$ nacido en Buenos Aires aunque de origen yugoslavo, es autor de un artículo sobre El defensor (1948), de Pedro Salinas, que acababa de reeditar Alianza en 1967, con una introducción de Juan Marichal. Soldatić comenta con solvencia los ensayos que componen el libro (haciendo referencia a tales ensayos aparecía subtitulada la primera edición), resumiendo su contenido y valor. Recuérdese que entre ellos se encuentra la célebre «Defensa de la carta misiva y de la correspondencia epistolaria». Pero Salinas también defiende la lectura de las minorías literarias y de los viejos analfabetos, no así la de los neoanalfabetos, dignos de compasión para él, ni tampoco de los que denomina neoanalfabetos parciales, a la vez que reflexiona sobre la crítica literaria. Y, por último, en otro trabajo, «Defensa del lenguaje», afirma que los poetas son quienes

18 Cf. Miguel Delibes y Francisco Umbral, La amistad de dos gigantes. Correspondencia (196o2007), prólogo de Santos Sanz Villanueva, Barcelona: Destino, 2021, 167.

19 La brasileña Valquiria Wey (1944) es ensayista y traductora. Se licenció en Letras Españolas en la UNAM, doctorándose en la misma institución en la que es profesora. Asimismo, es editora de la página cultural Terra Brasilis y pertenece al comité editorial de Cuadernos Americanos y al Sistema Nacional de Investigadores (SIN), además de ser miembro del Consejo Académico Consultivo del Colegio de Estudios Latinoamericanos (CELA).

20 Es catedrático de Estudios Ibéricos en la Universidad de Belgrado. Ha traducido al serbio obras de Galdós, Borges, R. J. Sender, Gonzalo Torrente Ballester y Juan Goytisolo, entre otros, y al castellano el Diccionario jázaro. Novela léxico (1989), de Milorad Pavić. 
utilizándolo llegan a su máxima expresión. ${ }^{21}$ Salinas concluye afirmando que «prescindir de los libros sería perder conciencia de pertenecer a lo histórico y condenarse a la desaparición en la memoria del futuro», algo que setenta años después no ha perdido vigencia. El profesor Soldatić nos dice que en este libro Pedro Salinas «emprende la ingrata tarea de defender ciertas tradiciones espirituales que ve amenazadas y con un futuro desconcertante».

El crítico y profesor estadounidense George E. Welwarth (1940) ${ }^{22}$ dedica grandes elogios a la obra de José Ruibal, quien acababa de obtener el premio que concedía la revista Modern International Drama por su pieza El asno (1962), aunque en esta ocasión sus comentarios se centran en El hombrey la mosca (1968), pues considera que forma parte de la corriente principal de la literatura europea contemporánea, con Genet o Ionesco a la cabeza, destacando en Ruibal su profundo conocimiento de la tradición española, su dominio de los recursos de la alegoría y de la fantasía, así como de la utilización de imágenes sobresalientes, pues la obra nos muestra «la quintaesencia de la realidad oculta tras la fachada de la vida». Welwarth concluye el artículo afirmando que El hombre y la mosca «lleva al teatro español a un punto en que puede competir honrosamente y en términos de igualdad con el mejor teatro que se escribe y representa en el mundo occidental».

El número se cierra con «Tres realizadores españoles», artículo dedicado a Luis García Berlanga, Mario Camus y Miguel Picazo, en el que José de Jesús Gama, ${ }^{23}$ tras una breve presentación, les cede la voz para que cuenten los

21 Andrés Soria Olmedo, en un trabajo de 1995, afirma que «probablemente [sea] el documento de reflexión sobre la lengua más importante y sostenido del siglo». Citado en Montserrat Escartín Gual, Pedro Salinas, una vida de novela, Madrid: Cátedra, 2019, 265.

22 Es profesor de Teatro y Literatura Comparada en la Universidad Estatal de Nueva York y autor de libros como Teatro de protesta y paradoja (Lumen, 1966) y Spanish Underground Drama (Villalar, 1978, con prólogo de Alberto Miralles), donde analiza el teatro simbolista. Ambos libros fueron muy influyentes en su momento. En Estados Unidos publicó cuatro antologías del teatro español, y es, además, el editor de la Modern International Drama, revista de la Universidad de Pensilvania, en la que han aparecido numerosas obras o fragmentos de autores españoles como José Ruibal, José Bellido, Luis Matilla, Antonio Martínez Ballesteros, Eduardo Quiles, Jerónimo López Mozo, Manuel Martínez Mediero, Ángel García Pintado y Juan Antonio Castro, así como de dramaturgos que escriben en catalán, como Manuel de Pedrolo, Josep Maria Benet i Jornet y Jordi Teixidor.

23 Siento no haber logrado encontrar dato alguno sobre el autor de este artículo. 
aspectos más significativos de su trayectoria cinematográfica. La elección de los nombres es ya en sí misma relevante, pues prescinde de Buñuel, Juan Antonio Bardem, Carlos Saura o Basilio Martín Patino. Berlanga había dirigido Esa pareja feliz (1951), junto a Bardem, Bienvenido, Mr. Marshall (1953) y El verdugo (1963), declarándose «anarquista feroz» y negando ser un autor comprometido. Mario Camus, que ya había estrenado Los farsantes (1963), Young Sánchez (1964) y Con el viento solano (1967), entre otras, se define como «un trabajador del cine», más partidario de la cinematografía americana (su director preferido era entonces Richard Brooks, quien había dirigido La gata sobre el tejado de zinc, 1958; Dulce pájaro de juventud, 1962, o A sangre fría, 1967) que de la europea, que tacha de intelectual y cuyas películas le parecen «cerebrales, aburridas, vacías». Por su parte, Miguel Picazo solo había estrenado dos películas: La tía Tula (1964), que le dio prestigio, y Oscuros sueños de agosto (1967), de las que se mostraba satisfecho. Considera que su cine forma parte de un movimiento formado por jóvenes realizadores procedentes de la Escuela de Cine, cuyos antecesores más cercanos eran Berlanga y Bardem. Aunque Picazo, en un momento dado de sus confesiones, señala que sus directores preferidos eran Luis Buñuel, C. T. Dreyer, Luchino Visconti, Stanley Kubrick, S. M. Eisenstein y Chaplin. Por otra parte, José Estrada mantiene una conversación con el cantante Raimon, en la que este afirma que el concepto de "canción protesta" es una etiqueta que no le gusta, teniendo que defender, ante la insistencia de su interlocutor, su deseo de cantar en valenciano, en catalán, su lengua, como una manera también de que las minorías culturales adquieran una vida normal. Señala, además, el auge que había vivido la cultura catalana en esos últimos seis o siete años en el mundo editorial y denuncia la censura que existía en España, que en su caso no se debía solo a la lengua, sino también a los temas que trata en sus canciones.

El número nos sirve también para hacernos una idea sobre las editoriales mexicanas que entonces se ocupaban de España (la UNAM, las Publicaciones de la Dirección General de Difusión Cultural, Joaquín Mortiz —anuncia las «obras incompletas» de Max Aub, compuestas por ocho textos-, el FCE y Era), sobre la presencia de los libros de autores españoles o sobre España en sus catálogos: los Juegos de escarnio, de Quevedo, Lope de Vega y el Arcipreste de Hita; la obra de León Felipe; la Poesía española en México, 
en audiolibro; el Romancero de la resistencia española, de Dario Puccini, publicado por Era en 1967; la Poesía española contemporánea, de Max Aub; La guerra de España, de Pietro Nenni; Así fue la defensa del Madrid, del general Vicente Rojo; Sierra de Teruel, de André Malraux; el guion de Viridiana, de Luis Buñuel; libros de ficción de María Teresa León y Agustí Bartra, y volúmenes de historia, como los de fray Bartolomé de las Casas (Apologética historia sumaria), Claudio Sánchez Albornoz (Estudios sobre las instituciones medievales españolas), Marcel Bataillon (Erasmo y España), Jean Sarrailh (La España ilustrada en la segunda mitad del siglo XVIII) y Carlos M. Rama (La crisis española del siglo XX). Muchos de estos libros estaban prohibidos en España y difícilmente eran asequibles para el lector español.

Tendríamos que preguntarnos por qué se hizo este número, qué se quería mostrar y qué idea pretendía darse de la literatura española a los mexicanos, pero también al resto de Hispanoamérica, e incluso a España, si es que los ejemplares de la revista conseguían salir de México, traspasar la densa barrera de la censura española. El número se centra en las letras españolas, sobre todo en las del interior, con escasas referencias a los escritores del exilio republicano, que tampoco colaboran en el monográfico; hay algunas a la literatura catalana y casi ninguna a la gallega y vasca. Se decanta por la narrativa y le presta menos atención al teatro y prácticamente nada al cuento y al ensayo. En cambio, aparece una entrevista con el cantante Raimon y un artículo dedicado al cine. Así, algunos de los defectos que se achacaban a las publicaciones del interior, sus prejuicios, se repiten en este monográfico, pues aquí apenas se tiene en cuenta las indiscutibles aportaciones de la literatura hecha fuera de España. Recuérdese, además, que en 1969 Max Aub estuvo en España algo más de dos meses, recogiendo materiales para su libro sobre Buñuel. De esa experiencia surge $L a$ gallina ciega. Diario español (1971). El contraste entre sus opiniones y las del número mexicano son más que notables. ${ }^{24}$ Por tanto, no era solo la censura española lo que impedía ofrecer una imagen completa de la cultura española, sino quizá también el desconocimiento, el amiguismo, la mera desidia o la carencia de una visión global y más compleja. Se perdió,

24 Véase ahora la reciente edición del libro, puesta al día, al cuidado de Manuel Aznar Soler, en la «Biblioteca del Exilio» de la editorial Renacimiento (Sevilla, 2021). 
así pues, una ocasión inmejorable para dar un panorama más matizado, sin olvidos de la cultura, de la literatura española, tanto de la que se había hecho en la península como lejos de ella, en sus distintas lenguas. ${ }^{25}$

Veamos, por último, qué pasaba entonces en México, más allá de su agitada historia en esos años, a la que ya nos hemos referido, y del gran crecimiento económico de que gozó durante los cincuenta, aunque no consiguiera paliar las grandes diferencias económicas y culturales de la población, a pesar de los indudables avances sociales, como ha recordado Valender. ${ }^{26}$ En ese mismo periodo de 1969, Max Aub publicó en el país que lo acogió la segunda edición ampliada - la primera data de 1954- de su estudio Poesía española contemporánea, en la editorial Era, ${ }^{27}$ mientras que en 1960 aparecería su antología Poesía mexicana. 1950-196o, en la que incluye a los siguientes exiliados: León Felipe, José Moreno Villa, Juan José Domenchina, Emilio Prados, Pedro Garfias, Juan Rejano, Luis Cernuda, Manuel Altolaguirre, Ernestina de Champourcín, Gabriel García Narezo, Francisco Giner de los Ríos, Nuria Parés, Manuel Durán y Tomás Segovia, componiendo una auténtica antología de la poesía del exilio republicano español en México. ${ }^{28}$

25 En 1961, Francisco Olmos publicó en el número 14 (p. 33-38) del Boletín de información de la Unión de Intelectuales Españoles, editado en México entre 1956 y 1961, el artículo «La nueva novela: presente y porvenir». Se refiere a la compuesta por obras de Rafael Sánchez Ferlosio, Juan Goytisolo (Juegos de manos, 1954, inicia esta tendencia), Jesús López Pacheco, Carmen Martín Gaite, Jesús Fernández Santos, Luis Goytisolo-Gay (como firmaba entonces), Juan García Hortelano, Antonio Ferres y José Corrales Egea. Todas ellas concuerdan, según Olmos, en lo fundamental, en «la necesidad ineludible de supeditar el arte a la vida y por ende la técnica al contenido». Quedan excluidos de esta tendencia Cela y Ana María Matute, junto a los narradores que compusieron sus obras en el exilio, con la excepción de Corrales Egea, quizá porque, a pesar de haberse exiliado en París, visitó España con frecuencia. Véase la edición del Boletín de Manuel Aznar Soler (Sevilla: Renacimiento, 2008).

26 Véase James Valender, «Max Aub y su antología de Poesía mexicana (1950-1960)», en James Valender y Gabriel Rojo, ed., Homenaje a Max Aub, México: El Colegio de México, 2005, 253 y 254, trabajo de sumo interés que he aprovechado todo lo que he podido.

27 Véase ahora la edición de Juan María Calles en Max Aub, Obras completas. Ensayos I, Valencia: Iberoamericana Vervuert, 2020.

28 Véase Valender, op. cit., 253-28o. En esta antología de los poetas españoles republicanos, Valender (p. 267) echa de menos a Concha Méndez y a otros miembros de la segunda generación, como Ramon Xirau (poeta en catalán), Luis Rius, Jomi García Acot, César Rodríguez Chicharro y Josep Pascual Buxó. Cuando, en el diálogo final, Xirau le pregunta a Max Aub por qué no están Pascual Buxó, Rius y Enrique de Rivas, le contesta algo displicente: «Si cada familia de refugiados ha 
Para esta panorámica de la época podemos partir de las ideas que ha defendido Segovia, poeta, narrador y ensayista hispanomexicano, perteneciente a los que solemos denominar "segunda generación", que colaboró en la revista Presencia, aunque en el ámbito estrictamente mexicano se le suele relacionar con una brillante hornada de la que forman parte escritores, críticos y ensayistas (Carlos Fuentes, Salvador Elizondo, Sergio Pitol, José Emilio Pacheco, Carlos Monsiváis y Juan García Ponce, entre otros) y pintores (José Luis Cuevas, Vicente Rojo o Rufino Tamayo). Todos ellos, durante los sesenta, junto a Octavio Paz, consiguieron renovar la cultura mexicana en la estela del universalismo pregonado por Alfonso Reyes, apostando por una literatura urbana, sin por ello menospreciar Pedro Páramo (1955), la obra maestra de Juan Rulfo, La feria (1963), de Juan José Arreola, o Los recuerdos del porvenir (1963), de Elena Garro, y alejándose del existencialismo, la obsesiva reflexión sobre la mexicanidad y la clásica cultura de la revolución (la obra de Mariano Azuela, Los de abajo, 1915; la poesía de Manuel Maples Arce o la pintura de Diego Rivera). ${ }^{29}$ Recuérdese que son los años en los que Miguel León Portilla da a conocer sus estudios y traducciones — hechas con el padre Ángel María Garibay en 1940- de la cultura náhuatl, propiciando un debate sobre qué temas debía abordar la literatura mexicana ${ }^{30} \mathrm{y}$ influyendo en la construcción de la identidad

procreado tres hijos, cuatro son poetas. A ellos y a otros los incluiré, si llegó a hacerlo, en el próximo volumen». Lamentablemente, no llegó a publicarlo (p. 278).

29 En su libro Itinerario (1993), Octavio Paz comenta: «Mi generación fue la primera que, en México, vivió como propia la historia del mundo, especialmente la del movimiento comunista internacional. Otra nota distintiva de nuestra generación: la influencia de la literatura española moderna [...]. Nosotros leíamos con el mismo entusiasmo a los poetas y a los prosistas, a Valle-Inclán, Jiménez y Ortega igual que a Gómez de la Serna, García Lorca y Guillén [...]. Por primera vez la tradición hispánica no era un obstáculo sino un camino hacia la modernidad». En la entrevista que le hizo Claude Fell, Paz sostiene: «La presencia de los intelectuales europeos, sobre todo de los españoles, en el México de la década de la guerra, fue muy benéfica. A ellos les debemos, en buena parte, la renovación de la cultura mexicana». En otra conversación con Héctor Tajamar (;Siempre!, marzo 1977), comenta que «lo que pasaba en España, desde el punto de vista literario [...], en la década de los cincuenta, no me interesaba mucho», con excepciones (Cela, Carlos Barral, Gil de Biedma, Juan Goytisolo y Pere Gimferrer), y que esa opinión cambió en los setenta, cuando en 1974 viajó a España y pudo conocer a Juan Benet y Julián Ríos. Todas estas referencias aparecen recogidas en Danubio Torres Fierro, ed., Octavio Paz en España, 1937, México: FCE, México, 2007, 56, 111 y 125.

30 Véanse los siguientes libros de León-Portilla: La filosofia náhuatl estudiada en sus fuentes (1956), Siete ensayos sobre cultura náhuatl (1958), Visión de los vencidos (1959) y Los antiguos mexicanos a través de sus crónicas y cantares (1961). Según Valender (op. cit., 256-257), la poesía náhuatl influyó 
de los mexicanos. A su vez, también afectó a los españoles que quisieron integrarse en la sociedad y en la cultura del país. ${ }^{31}$ Max Aub, en el prólogo a su citada antología de 1960, afirmaba que uno de los mayores logros de la Revolución Mexicana fue el hecho de que, con algunos de sus líderes, hubiera accedido al poder por primera vez el mestizaje, propiciando décadas después la revalorización de la cultura indígena.

Los ídolos de entonces entre los jóvenes seguían siendo - siempre según Tomás Segovia— José Revueltas (Los días terrenales, 1949) y Agustín Yáñez (Al filo del agua, 1947), ${ }^{32}$ si bien pronto tomarían el relevo Juan José Arreola (Confabulario, 1952), la poesía de Álvaro Mutis — su narrativa es posterioro bien la prosa singular de Augusto Monterroso (Obras completas y otros cuentos, 1959; La oveja negra y demás fábulas, 1969). También destacarían los libros de Carlos Fuentes, la antología Poesía en movimiento. México, 19151966 (1966), de Octavio Paz (autor también del prólogo), Alí Chumacero (responsable de las notas, con Pacheco), ambos poetas consagrados, y los jóvenes Homero Aridjis y José Emilio Pacheco, que «fue un parteaguas», al decir de Segovia, pues vino a sustituir en el canon a la Antología de la poesía mexicana moderna (1928, con una reedición en 1952), de Jorge Cuesta, y pudo confrontarse con la antología contemporánea de Carlos Monsiváis, La poesía mexicana del siglo XX (1966). ${ }^{33}$ Entre los cuarenta y dos

en los relatos de Ermilo Abreu Gómez (Canek, 1940, y Quetzalcóatl, sueño y vigilia, 1947), los poemas de Antonio Mediz Bolio (la reedición de La tierra del faisán y del venado), de Andrés Henestrosa (Los hombres que dispersó la danza, 1946) y, sobre todo, de Octavio Paz (Piedra de sol, 1957), a los que podríamos sumar los nombres de Carlos Pellicer, Marco Antonio Montes de Oca y Rosario Castellanos, a quienes se alude a este respecto en el apéndice (p. 274 y 280) al citado artículo.

31 Véase José Gaos, «La adaptación de un español a la sociedad hispanoamericana», Revista de Occidente 13, núm. 38 (mayo 1966): 168-178.

32 Esta obra la reseñó Manuel Altolaguirre en «Agustín Yánez, novelista», artículo publicado en 1950 en México en la Cultura (núm. 78), suplemento del diario Novedades (México). La crítica está recogida en Manuel Altolaguirre, Obras completas, vol. 1, El caballo griego. Crónicas y artículos. Estudios literarios, edición de James Valender, Madrid: Istmo, 1986.

33 Gabriel Zaid afirma: «Poesía en movimiento [...], por su calidad y por ser la última en aparecer, resulta la antología culminante de un año de antologías. Comparada con la de Monsiváis, es inferior desde el punto de vista informativo y cubre menos poetas mayores de cuarenta años (20 en vez de 38). En cambio, tiene a favor la generosidad con los jóvenes (22 en vez de 7 poetas de menos de cuarenta años); la mejor selección de poemas; [...] ciertas innovaciones (invertir el orden cronológico de presentación de poetas, incluir a Torri y Arreola, como poetas en prosa)». Citado en Miguel Rupérez Pascual, «La fijación del canon de la poesía mexicana del siglo xx a través de las antologías: el caso de Poesía en movimiento», Tonos digital 28 (2015). 
poetas que aparecen, se encuentran los exiliados Manuel Durán y Tomás Segovia, quizá por su formación poética mexicana y porque el criterio de la nacionalidad resultaba insuficiente al prologuista en un país que hizo suyos a escritores procedentes de otros lugares, como el guatemalteco Monterroso, el colombiano Mutis y los nicaragüenses Salomón de la Selva y Ernesto Mejía Sánchez. Si algunos estimaron que fue Octavio Paz y no Alfonso Reyes quien trajo la modernidad a México, fue porque aquel supo mostrar mejor en su poesía y en sus ensayos el carácter mestizo de la cultura mexicana, conjugando en ella tanto los valores indígenas como los españoles.

Tomás Segovia se había formado en la UNAM y en El Colegio de México, con Raimundo Lida, y no volvió a España hasta 1976. Sobre la situación de la literatura en México durante los años sesenta, es necesario recordar, además, que entre 1958 y 1963 nuestro poeta había dirigido la Revista Mexicana de Literatura, fundada en 1955 por Carlos Fuentes (La región más transparente, 1958, y La muerte de Artemio Cruz, 1962), quien lo designó como sucesor. Para continuar la empresa, Tomás Segovia contó con el apoyo de Octavio Paz, Gabriel Zaid y los jóvenes escritores de su generación. Además, a partir de 1961 dirigió la Casa del Lago, centro cultural de la Universidad, situado a orillas del lago Chapultepec, aunque pronto, entre 1961 y 1963, se fue a vivir a Montevideo. O sea, que en diversos momentos de su vida siempre nómada Segovia pudo observar tanto México como España desde la distancia, con una perspectiva diferente y enriquecedora, de forma semejante a como Octavio Paz y Aridjis compusieron Poesía en movimiento desde la India y los Estados Unidos, respectivamente - aunque la contribución del segundo sabemos que fue modesta. Son los años de la superación del nacionalismo, de la recuperación del grupo de los Contemporáneos (que se desarrolló entre 1928-1931, con José Gorostiza, Xavier Villaurrutia, Salvador Novo, Carlos Pellicer, Gilberto Owen, Jaime Torres Bodet, Jorge Cuesta, Antonieta Rivas Mercado y Bernardo Ortiz de Montellano, entre otros) y de las dos grandes revistas de Octavio Paz: Plural, en la que Segovia fue redactor jefe durante 1971 y 1972, y Vuelta. También fue quizá una época de un cierto desinterés de México por el exilio español, centrados en sus propias tragedias y pendientes del optimismo que generó la celebración de las Olimpiadas. La formación poética mexicana de Tomás Segovia pasa por Ramón López Velarde, el poeta nacional, el 
más popular Xavier Villaurrutia, José Gorostiza (el autor de Muerte sin fin, 1939), los citados Contemporáneos o Gilberto Owen, y finalmente por el grupo que se gestó alrededor de Octavio Paz, obsesionado con la idea, de procedencia francesa - recuerda Segovia-, de que una generación tenía que dejar huella haciendo una revista notable, por «hacer de los mexicanos contemporáneos de todos los hombres». Se trataba, en suma, de un ambicioso empeño, pues aspiraban a modernizar y a democratizar el país.

$\mathrm{Al}$ mismo tiempo, los principales referentes de Tomás Segovia entre los exiliados españoles fueron Emilio Prados, su primer maestro, y luego Juan Ramón Jiménez y Luis Cernuda. Respecto a los escritores del interior, afirmaba mantener afinidades con los poetas del medio siglo, sobre todo con Claudio Rodríguez, aunque no creía que perteneciera a esa generación. ${ }^{34}$ Así, en Literatura de los niños de la guerra del exilio español en México (1996, p. 80-81), le confiesa a Mateo Gambarte: «Nuestra generación es desconocida aquí y allí. En México, como círculo cerrado y doliente, se distanció, o mejor dicho, los poetas mexicanos se distanciaron de nosotros, aquí simplemente nos ignoran». Sin embargo, el FCE publicó su poesía completa en 1982 y en 1998, y encontró en Ediciones Sin Nombre, de México, y más tarde en Pre-Textos, de España, editores que le fueran fieles.

En conclusión, una revista mexicana le dedica un monográfico a la cultura española en 1969, fecha histórica y literaria clave en el mundo, en México y en España, poniendo en juego o prescindiendo de los escritores y ensayistas del interior y del exilio, de modo que, si queremos comprender cuál fue su aportación, no debemos perder de vista la triple realidad de la cultura española, la actualidad mexicana y lo que representaron los exiliados republicanos. 35

34 Véase Tomás Segovia, Apalabrarse, México: Ediciones Sin Nombre, 2012, 18-20, 42, 71-72, 76, 87-93 y 98; Eduardo Mateo Gambarte, Literatura de los niños de la guerra del exilio español en México, Lleida: Pagès Editors, 1996, 40, 69, 80-84, 90-93, 100, 129, 130, 190 y 191, y Eduardo Mateo Gambarte, Diccionario del exilio español en México. De Carlos Blanco a Ramón Xirau, Pamplona: Eunate, 1997, 241-256.

35 Quiero darles las gracias por su ayuda a Olívia Gassol, Sonia Hernández, la joven estudiosa mexicana Liliana Muñoz, Germán Gullón y Gemma Pellicer. 